\title{
Games for Empathy for Social Impact
}

\author{
https://doi.org/10.3991/ijep.v6i4.6064 \\ Chara Papoutsi, and Athanasios S. Drigas \\ NCSR DEMOKRITOS, Institute of Informatics and Telecommunications, Net Media Lab, Athens, Greece
}

\begin{abstract}
Technology is changing and affecting the world around us from all angles. Information and Communication Technologies (ICTs) constitute suitable tools for interventions with children and adolescents promoting their emotional, psychological and social wellbeing. However, many good reasons underlie the conviction that digital simulations and games are particularly effective media for developing empathy. The current article aims to carry out a systematic review of ICTs on evoking empathy through games.
\end{abstract}

Index Terms-ICTs, Empathy, Emotion Recognition, Games, Social Change, Bullying

\section{INTRODUCTION}

Information and Communication Technologies (ICTs), namely technical devices that facilitate the rapid collection, collation, storage, and dissemination of data, assisting knowledge creation and diffusion are beginning to emerge as a valuable resource in the promotion of healthy and safe behaviors [1]. The huge development of ICTs have contributed to a cultural change involving economic and industrial activities as well as social and relational domains. It also provides several benefits to promote people's and children's wellbeing.

Digital games are such a popular and influential medium for a combination of many factors. Games, while being fun, entertaining and attractive, are also used to teach traditional subjects (e.g. math, science, chemistry) and help improve ICT skills. They are also able to convey serious contents such us teaching a specific subject (e.g. traffic education), increasing awareness on a particular social phenomenon (e.g. racial prejudice, bullying) or promoting sustainable behavior (water wasting). Furthermore digital games are increasingly used to promote health and manage disability in clinical settings. In addition they have positive effects in social interactions too. When appropriately designed, they also have a potential to foster players' metacognitive regulation and engage them in active cognitive thinking.

Moreover there are many good reasons underlie the conviction that digital games are particularly effective for developing insight, empathy, prosocial skills and improve behavior in many domains. Games offer unique opportunities for active and experiential learning and they can teach socioemotional skills. Empathy may be further developed when a player not only takes the perspective of another but also begins to identify with the character represented. There are games that are intended only for the cultivation of empathy but there are other games that along with the other objectives inherent and the assessment, intervention and development of empathy.

The term empathy was coined by Titchener (1909) as a translation form the German word "Einfühlung" to describe the process of perceptually seeing something from the inside [3]. Today, empathy researchers define empathy commonly as "an emotional response that stems from another's emotional state or condition and is congruent with the other's emotional state or condition" [4], [2]. Empathy requires both the ability to share the emotional experience of the other person (affective component) and an understanding of the other person's experience (cognitive component). Empathy allows us to understand the feelings of others, predict their behaviors and experience emotions triggered by their emotions.

Cohen and Strayer also define empathy as "the ability to understand and share in another's emotional state or context". The perception of the concept of empathy varies from an emotional response to others' feelings to the cognitive ability to understand these feelings. In addition to these two often - used major components of cognitive and affective empathy, a dimension for empathy in fictional contexts broadens the concept [5].

The current article presents an overview with the most representative studies and focuses on games that have as a primary or secondary target the detection and cultivation of empathy on various and important issues. These games have been expanded in the fields mentioned underneath: Games for Social Change and Games for Bullying. The sectors chosen will be classified according to the areas of needs they serve.

\section{GAMES FOR EMPATHY}

\section{A. Games for Social Change}

Belman et al., (2010) presented three games to cultivate empathy. The games are: "Peacemaker", "Hush" and "Layoff". In "Peacemaker" the player inhabits the role of either the Israeli Prime Minister or Palestinian President during a particularly volatile period of the PalestinianIsraeli conflict. Whichever role the player chooses, the goal is to create conditions in which a "two-state solution" to the conflict becomes viable. The user has to negotiate peace by making political, economic, and security decisions while the game presents the players with unexpected events [AI (Artificial Intelligence) actions] such as Palestinian suicide bombings or Israeli air strikes. There are a wide variety of actions to choose from, some hawkish, some conciliatory, some unilateral, and some that require cooperation with groups on the other side of the conflict. The game encourages empathy in several ways [6], [7].

"Hush" begins with a screen prompting us to take the perspective of the player character, who is a Rwandan Tutsi mother hiding in a shack with her baby during the genocide of 1994. Against a background of haunting music, this message appears: Rwanda, 1994: The Hutu are coming, Liliane. Hide your child. If you falter in your lullaby, he will grow restless. The soldier will hear him, and he will come for you. By addressing the player as "Liliane," the game encourages players to forego the emo- 
tional distance that usually separates them from what happens on screen. This can be regarded as a kind of empathy induction, in response to which we may be more likely to inhabit, explore, and identify with Liliane's experience [6].

"Layoff" is designed to elicit empathy in players towards characters in the game. In Layoff, one plays as "corporate management," tasked with cutting jobs during the financial crisis. When players match sets of three or more workers, they fall off the bottom end of the board into an "unemployment office." The game, however, is designed to challenge this perspective, to contend with the idea that a worker is only a "part." Each worker has a detailed personal biography that pops up when their tile is selected. In Layoff a bond of empathy is created not between the player and player character (who in Layoff, represents management), but rather between the player and non-player characters (i.e., the workers who are being laid off) [6].

Gordon et al., (2011) studied the implementation of "Participatory Chinatown" a 3D, multiplayer game designed to be played in the shared physical space of a master planning meeting in Boston's Chinatown neighborhood. "Participatory Chinatown" demonstrates that roleplay can engage players in local issues and motivate them to engage with each other and with their community. When playing the game, participants empathize with the needs and desires of a character and make decisions accordingly [8].

Bachen et al., (2012) examined "REAL LIVES", a game that allows learners to live simulated lives in other countries and to develop global empathy, identification, and interest in learning about other countries. Students can vicariously experience what life could be like for a male or female in another country, including education, employment, marriage, having children, confronting diseases and natural disasters, and so on. The software uses realworld data to determine the probability of events that are likely to happen in the character's life in their particular birth country. "REAL LIVES" contains elements that could foster the cognitive, affective, and communicative components of global empathy [9].

Ducheneaut et al. (2005) described "Everquest Online Adventures (EQOA)", a game belongs to Massively Multiplayer Online Role Playing Games (MMORPGs). The game takes place on a single continent, Tunaria, in the larger world of Norrath. Players select a "race" (e.g. elf, human, dwarf, etc.) and a "class" (e.g. wizard, warrior), both of which will affect their attributes and abilities. Players then take control of an "avatar" or virtual body in an elaborate 3D space, where they battle a variety of creatures and accomplish quests to progress in the game and develop their character. The game provides many opportunities for learning social skills and that includes empathy too through social interactions [10].

Dahya (2009) presented three games: "Darfur is Dying, 2006", "Ayiti: The Cost of Life, 2006", "Replay: Finding Zoe, 2007" and "Homeless: It's No Game, 2006". "Darfur is Dying" focused on the tyranny of the militia, represented through the act of foraging for water in the desert while armed men hunted the avatar down. The author took a third-person perspective both guiding and watching her avatar across the desert floor. "Ayiti: The Cost of Life" took the concept of poverty as an obstacle to education and created an environment where a family of five lives in poverty-stricken rural Haiti. The goal is to survive for four years, divided into sixteen seasons, focusing on health, education, money, and/or happiness. "Homeless: It's No Game" presented an environment related to a homeless person, based on the inherently human feeling of selfesteem. The intention of the game was to provide a space where empathy with the difficulties faced by homeless people could be generated. "Replay: Finding Zoe" is about an avatar that must find Zoe, who was suspected to be in an abusive relationship with her boyfriend, Jake. One of the main intentions of these games is to provoke empathy and to arouse emotion understanding in each situation [11], [12].

Shaffer (2005) presented "Madison 2200", a game where players learn about urban ecology by working as urban planners to redesign a downtown pedestrian mall popular with local teenagers. Characters in this game are designed based on real human experiences in urban places and the players through activities are feeling like doing something in the world within community of practice. Once players have full control over the appearance of their characters, they might be expected to identify more with their characters and therefore be more likely to develop empathy [13], [14].

Sharp (2012) presented the game "Squeezed" where the player takes on the role of a tree-hopping, bandanawearing frog who leaves home to seek work abroad as a fruit picker, experiencing the trials and tribulations of living in a foreign country, under highly oppressive conditions, and preoccupied with the thought of sending monies back home to the family. The games contains global matters and provoke emotions and empathy to the player who is takes the place of another creature and experience the difficulties that any other people have [15].

DeRosier et al. (2012) described the design and evaluation of "Zoo U", a novel computer game to assess children's social skills development and build social emotional skills. Through adaptive, personalized game play, children navigate social situations in a virtual world for future zoo keepers to learn essential social emotional skills for the real world, including communication, cooperation, and empathy. The animals provide a bit of fun and fantasy to the school setting as well as opportunities for novel social problem solving tasks [16].

Boltz et al. (2014) introduced "Migrant Trail". "The Migrant Trail" is a single-player simulation game examining the life of migrants and border patrol agents on the U.S.-Mexico border. The player may choose to play as one of several individuals on either side and is always first introduced to a prologue explaining that character's history and motivations. As a border patrol agent, the player drives one of those same patrol cars, searching for groups attempting to cross the border. Once a group or individual is found, much of the player's time - a limited resource for border agents - can be spent tending to injuries and ensuring captured migrants receive proper care, for the objective of the border patrol agent is not simply to capture as many migrants as possible, but also to prevent deaths and injuries. When switching from migrant to border patrol, the focus on providing aid combined with an understanding of how brutal conditions are for migrant groups produces empathy and drives the player towards success from a humanitarian perspective [17]. 
Pope (2013) created "Papers, Please", a game where the player took on the role of a border guard at a fictional Eastern European country, "Arstotzka," during the fall of the Soviet Union. Their job was to inspect the documents that were presented and examine them for inconsistencies, such as incorrectly declared genders or weights. Then, the documents were checked against a protocol for acceptance - a protocol that became more complex every ingame day. Furthermore every day, meeting all the needs of family's border guard costed a certain amount of money, and anything else was added to his bank balance to cover future problems. The eventual ending they get depends on how well they succeed in making it through the game without being arrested, fired, and with their family intact and healthy. Players are forced to make difficult moral choices, balancing empathy for the people they encounter in their job with the need to keep their family healthy, warm. The game inviting players to develop the cognitive skills necessary to consider alternate points of view and the circumstances that shape the actions of others, as well as activating a sense of shared similarity and empathic concern for individuals and groups with whom they may not have direct contact [18].

Smethurst et al. (2014) performed "The Walking Dead", an ongoing point-and-click adventure game series, developed and published by Telltale Games from 2012 onward. "The Walking Dead" is set in present-day Georgia, USA, which, as the game's title suggests, is in the process of being overrun by zombies. The player takes control of Lee Everett, a thirtysomething former history professor who must weather the zombie apocalypse by banding together and cooperating with other survivors in order to secure food and shelter. Apart from the action scenes the gameplay revolves around managing interpersonal relationships and mediating conflicts, solving environment-based puzzles, making difficult decisions regarding survival (whom to take and whom to leave behind on scavenging missions, who should receive food rations, and so on), and trying to preserve the lives of as many of the other survivors as possible. The game works hard to make the player feel both emotional and cognitive empathy toward the characters [19].

Mitgutsch et al. (21012) presented "Sweatshop", a free online game, talking about human exploitation on factories. Through a series of thirty challenging levels, players must balance the unreasonable demands of Boss, the temperamental factory owner and Boy, a gentle, hard-working child labourer. The game presents a series of moral dilemmas to the player, who must juggle the needs of the demanding clients with the welfare of workers. Sweatshop offers an accurate picture of the lives of those who work in the system, the factory owners and managers. The game is littered with real facts about the fast fashion industry and aims to provoke teenagers into thinking about their fashion choices more carefully and cultivate peoples' consciousness and empathy for the working conditions of those people [20].

Abraham (2014) described "Fate of the World" a game about Global Warming which aims to bring the political and environmental struggles of climate change to life. As the head of the fictional Global Environment Organization (GEO), you have a budget to employ agents in different world regions and task them with promoting projects, ranging from encouraging a switch to electric cars to opening a regional aid office. Players will explore geoen- gineering, alternative energy sources and other options for protecting the planet over the next 200 years. By incorporating realistic predictions from climate models and advice from scientists, the game's developers, Red Redemption, hope to encourage players to engage with climate-change issues and to influence their attitudes and behaviors [21].

Hermund et al. (2011) created "3rd World Farmer", a game that illustrates the plight of poor farmers in impoverished countries. "3rd World Farmer" touches on many subjects related to world hunger and poverty. These subjects are brought into play through an intuitive and easyto-play simulation, where the player makes choices primarily about crop types, livestock, tools, and structures for his farm, as well as managing the family members' health, education, marriages and jobs. The game is educational and also intends to cultivate empathy and social awareness for these issues [22].

Van Looy et al. (2010) described "Poverty Is Not a Game (PING)", a 3D adventure game which represents an average Western European city in which the player takes the identity of one of two youngsters, Sophia or Jim, who find themselves in a difficult situation. The game involves finding your way around in PING city, find a place to live, work, education and perhaps even the partner of your dreams. It hopes to raise consciousness concerning the mechanisms underlying poverty and social exclusion and is specifically aimed at what is sometimes referred to as the fourth world [23].

\section{B. Games for Bullying}

Salmivalli et al. (2010) presented "KiVa program" which is an anti-bullying prevention and intervention program. "KiVa" universal actions include a series of student lessons given by classroom teachers and computer games. The main aims of the student lessons and computer games are to raise awareness of the role bystanders play in the bullying process, to increase empathic understanding of the victim, to provide safe strategies to support and defend the victims and to encourage students to make use of their knowledge and skills that obtained in real-life situations. The findings showed that "KiVa" significantly reduced both victimization and bullying, and it has also secondary effects on psychological symptoms and school climate [24], [25].

Aylett et al. (2006) presented "FearNot!" application software (Fun with Empathic Agents to Achieve Novel Outcomes in Teaching), an immersive learning intervention aimed to help victims to escape victimization, and to reduce overall bullying and victimization. The software considered the application of 3D animated synthetic characters and emergent narrative to create improvised dramas to address bullying problems for children aged 8-12 in the UK, Germany and Portugal. One of the main aims of the software was to develop synthetic characters that could, through their appearances, behaviors and features allow the user to build empathic relations with them. The software's pedagogical objectives were met through the design and implementation of interactive, episodic and emergent Memarzia scenarios in a safe school-based Virtual Learning Environment (VLE) [26], [27], [28].

Rubin-Vaughan et al. (2011) introduced "Quest for the Golden Rule", an anti - bullying prevention and intervention program composed by a web - based game, guides for teachers on software use, targeted curricula and follow - up activities. The interaction between children and the 
animated characters provides them the opportunity to learn and practice social skills and try out different strategies to cope with bullying. Three modules have been designed each addressing a different topic related to bullying prevention: Bark Academy, Mission to Mars and Ghoul School. Students with fun and interactive way have a collective experience that helps them have a healthy social development, practice social skills and foster empathy [29].

Memarzia et al. (2011) presented "Choices and Voices", a role-playing game in which players can experiment with peer pressure management and resistance strategies, decision making in moral dilemmas, and critical assessment of advice. The game engage young people in exploring and discussing issues underlying violent extremism such as peer pressure, social exclusion and bullying. Choices and Voices is divided into two short scenarios, with each scenario split into a series of acts and scenes. The scenarios take place in a multicultural population in the West Midlands and the player is a local resident and school pupil, with consequent versions made to reflect a range of other regions. The players interact with characters in a virtual community that reflects real life situations and through them feelings are aroused, empathy is evoked and the pupils come up with different issues and decisions [30].

Yannakakis et al. (2010) described Siren project, a European project aimed at creating an adaptive serious game for teaching conflict resolution. The Siren game consists of various technical components: adaptation, storytelling, emotional agent framework, natural interaction, and group modeling. The SIREN project aims to create a new type of educational game, "The Conflict Resolution Game", which takes advantage of recent advances in serious games, social networks, computational intelligence and emotional modelling to create uniquely motivating and educating games that can help shape how children think about and handle conflict. The software developed by the project will be able to automatically generate conflict scenarios such us school bullying that fit the teaching needs of particular groups of children with varying cultural background, maturity, and technical expertise, and the desired learning outcomes as specified by a teacher. Empathy and emotional engagements are key factors [31], [32].

\section{CONCLUSIONS}

The widespread use of information technology in everyday life is changing expectations, requirements and opportunities for people's lives.

Empathy becomes one of the primary outcomes of ICTs as far as cognitive and emotional abilities are concerned. Empathy is without question an important ability. It allows us to tune into how someone else is feeling, or what they might be thinking. Empathy allows us to interact effectively in the social world and helps us become aware of different important issues.

The articles reviewed above discussed the application of innovative computer games to assessment, intervention and cultivation of empathy. There has been conducted great progress in the design and the development of ICT games to provide children and adolescents the opportunity and the capability to develop empathy.
Thus, while we can point to some encouraging research, more studies are needed to determine whether and how games can help develop empathy, the role of identification in building empathy, and whether empathy and identification are associated with increased interest in global learning. The need for empathy is immense, and this is a need that education can address. Empathy could be analyzed in a long-term study, achieving greater accuracy by studying more messages and by studying the evolution of the community. Games may be just one of many such avenues for this purpose, and towards this goal, all potential avenues are worthy of attention. A consistent finding in the research literature is that empathy improves people's attitudes and behaviors towards other individuals or groups, while a lack of empathy is associated with more negative attitudes and behaviors.

Overall, considering the enormous development of digital tools the review underlines that ICT tools do play a significant role in ensuring and enhancing empathy to achieve more in social impacts, in bullying, in learning process, in human - computer interaction, in virtual environments etc.

\section{REFERENCES}

[1] Zamboni, L., Gamberini, L., Spagnolli, A., Cipolletta, S., De Giuli, G., \& Tion, I. (2011, September). Serious games in social intervention: designing technologies to promote safe and healthy behaviors. In Proceedings of the 9th ACM SIGCHI Italian Chapter International Conference on Computer-Human Interaction: Facing Complexity (pp. 139-142). ACM https://doi.org/10.1145/2037296. 2037330

[2] Happ, C. (2013). Empathy in video games and other media.

[3] Batson, C. D., \& Shaw, L. L. (1991). Encouraging words concerning the evidence for altruism. Psychological Inquiry, 2(2), 159168. https://doi.org/10.1207/s15327965pli0202_17

[4] Eisenberg, N., Shea, C. L., Carlo, G., \& Knight, G. P. (1991). Empathy-related responding and cognition: A "chicken and the egg" dilemma. Handbook of moral behavior and development: Research, 2, 63-88.

[5] Happ, C., Melzer, A., \& Steffgen, G. (2011). Bringing empathy into play: On the effects of empathy in violent and nonviolent video games. In Entertainment Computing-ICEC 2011 (pp. 371-374). Springer Berlin Heidelberg https://doi.org/10.1007/978-3-64224500-8_44

[6] Belman, J., \& Flanagan, M. (2010). Designing Games to Foster Empathy. International Journal of Cognitive Technology, 15(1), 11.

[7] Alhabash, S. E., \& Wise, K. (2012). PeaceMaker: changing students' attitudes toward Palestinians and Israelis through video game play. International Journal of Communication, 6, 25.

[8] Gordon, E., \& Schirra, S. (2011, June). Playing with empathy: digital role-playing games in public meetings. In Proceedings of the 5th International Conference on Communities and Technologies (pp. 179-185). ACM. https://doi.org/10.1145/2103354. $\underline{2103378}$

[9] Bachen, C. M., Hernández-Ramos, P. F., \& Raphael, C. (2012). Simulating REAL LIVES: Promoting global empathy and interest in learning through simulation games. Simulation \& Gaming https://doi.org/10.1177/1046878111432108

[10] Ducheneaut, N., \& Moore, R. J. (2005). More than just'XP': Learning social skills in massively multiplayer online games. Interactive Technology and Smart Education, 2(2), 89-100. https://doi.org/10.1108/17415650580000035

[11] Dahya, N. (2009). Serious learning in playful roles: Socio-political games for education and social change. Loading..., 3(4).

[12] Peng, W., Lee, M., \& Heeter, C. (2010). The Effects of a Serious Game on Role-Taking and Willingness to Help. Journal of Communication, 60(4), 723-742. https://doi.org/10.1111/j.14602466.2010.01511.x 
[13] Shaffer, D. W. (2005). Epistemic games. Innovate: Journal of Online Education, 1(6), 2.

[14] Williamson, D., Squire, K., Halverson, R., \& Gee, J. P. (2005). Video games and the future of learning. Phi Delta Kappan, 87(2), 104-111.

[15] Sharp, L. A. (2012). Promoting Community Service and global awareness through gamucation. SOCIAL RESPONSIBILITY, 24.

[16] DeRosier, M. E., Craig, A. B., \& Sanchez, R. P. (2012). Zoo U: A stealth approach to social skills assessment in schools. Advances in Human-Computer Interaction, 2012, 22. https://doi.org/10.1155/2012/654791

[17] Boltz, L. O., Henriksen, D., \& Mishra, P. (2014). Rethinking Technology \& Creativity in the 21 st Century: Empathy through Gaming-Perspective Taking in a Complex World. TechTrends, 59(6), 3. https://doi.org/10.1007/s11528-015-0895-1

[18] Pope, L. (2013). Papers, Please.

[19] Smethurst, T., \& Craps, S. (2014). Playing with Trauma Interreactivity, Empathy, and Complicity in The Walking Dead Video Game. Games and Culture, 1555412014559306.

[20] Mitgutsch, K., \& Alvarado, N. (2012, May). Purposeful by design?: a serious game design assessment framework. In Proceedings of the International Conference on the foundations of digital games (pp. 121-128). ACM.

[21] Abraham, B. (2014). Videogame Visions of Post-Climate Change Futures.

[22] Hermund, F., Nielsen, J. E., \& Toubro, O. F. K. (2011). 3rd World Farmer.

[23] Van Looy, J., Wouters, W., \& De Grove, F. (2010). Poverty is not a game (PING): demonstration of a serious game about the experience of being poor. In Fun and Games 2010. Fun and Games 2010.

[24] Salmivalli, C., Kärnä, A., \& Poskiparta, E. (2010). Development, evaluation, and diffusion of a national anti-bullying program, KiVa. Handbook of youth prevention science, 238-252.

[25] Salmivalli, C., \& Poskiparta, E. (2012). KiVa antibullying program: Overview of evaluation studies based on a randomized controlled trial and national rollout in Finland. International Journal of Conflict and Violence, 6(2), 293-301.

[26] Aylett, R., Louchart, S., Dias, J., Paiva, A., Vala, M., Woods, S., \& Hall, L. (2006). Unscripted narrative for affectively driven characters. Computer Graphics and Applications, IEEE, 26(3), 4252. https://doi.org/10.1109/MCG.2006.71

[27] Zoll, C., Enz, S., Schaub, H., Aylett, R., \& Paiva, A. (2006, April). Fighting bullying with the help of autonomous agents in a virtual school environment. In 7th International Conference on Cognitive Modelling.
[28] Vannini, N., Enz, S., Sapouna, M., Wolke, D., Watson, S., Woods, S., ... \& Aylett, R. (2011). "FearNot!": a computer-based antibullying-programme designed to foster peer intervention. European journal of psychology of education, 26(1), 21-44. https://doi.org/10.1007/s10212-010-0035-4

[29] Rubin-Vaughan, A., Pepler, D., Brown, S., \& Craig, W. (2011). Quest for the Golden Rule: An effective social skills promotion and bullying prevention program. Computers \& Education, 56(1), 166-175. https://doi.org/10.1016/j.compedu.2010.08.009

[30] Memarzia, M., \& Star, K. (2011). Choices and Voices-A Serious Game for Preventing Violent Extremism. In Intelligence Management (pp. 133-142). Springer London. https://doi.org/10.1007/ 978-1-4471-2140-4 9

[31] Yannakakis, G. N., Togelius, J., Khaled, R., Jhala, A., Karpouzis, K., Paiva, A., \& Vasalou, A. (2010). Siren: Towards adaptive serious games for teaching conflict resolution. Proceedings of $E C G B L, 412-417$

[32] Berger, F., Liapis, A., \& Yannakakis, G. (2012). Prototyping an adaptive educational game for conflict resolution. In ITS 2012 Workshop: Emotion in Games for learning.

\section{AUTHORS}

Athanasios Drigas is a Research Director at IIT, N.C.S.R. Demokritos. He is the Coordinator of Telecoms Lab and founder of Net Media Lab since 1996. From 1990 to 1999 he was the Operational manager of the Greek Academic network. He has been the Coordinator of Several International Projects, in the fields of ICTs, and eservices (e-learning, e-psychology, e-government, einclusion, e-culture etc). He has published more than 270 articles, 7 books, 25 educational CD-ROMs and several patents. He has been a member of several International committees for the design and coordination of Network and ICT activities and of international conferences and journals. Also he has accepted several distinctions for his work (articles, projects, patents) (e-mail: dr@iit.demokritos.gr).

Chara Papoutsi (MA in Applied Pedagogy) is a teacher in a primary school. She is also with NCSR DEMOKRITOS, Institute of Informatics and Telecommunications, Net Media Lab, Athens, Greece. (e-mail: xara.papoutsi@yahoo.com).

Submitted 20 July 2016. Published as resubmitted by the authors 23 September 2016. 